\title{
Evaluation of a 3-base pair indel polymorphism within pre-microRNA-3131 in patients with prostate cancer using mismatch polymerase chain reaction-restriction fragment length polymorphism
}

\author{
MOHAMMAD HASHEMI ${ }^{1,2}$, GHOLAMREZA BAHARI ${ }^{2}$, HEDIEH SATTARIFARD ${ }^{2}$ and BEHZAD NAROUIE $^{3}$ \\ ${ }^{1}$ Cellular and Molecular Research Center; ${ }^{2}$ Department of Clinical Biochemistry, School of Medicine, Zahedan University \\ of Medical Sciences, Zahedan 98167-43181; ${ }^{3}$ Urology and Nephrology Research Center, Department of Urology, \\ Shahid Labbafinejad Medical Center, Shahid Beheshti University of Medical Sciences, Tehran 198396-3113, Iran
}

Received April 4, 2017; Accepted August 2, 2017

DOI: $10.3892 /$ mco.2017.1369

\begin{abstract}
The present study aimed to examine the impact of a 3-bp indel (rs57408770) polymorphism within the pre-microRNA (miR)-3131 polymorphism on prostate cancer (PCa) risk in a sample of an Iranian population. In total, 340 subjects, including 177 patients with PCa and 170 patients with benign prostatic hyperplasia, were enrolled in the present case-control study. A mismatch polymerase chain reaction-restriction fragment length polymorphism method was designed for genotyping the 3-bp indel (rs57408770) polymorphism. The present findings demonstrated that the indel variant significantly increased the risk of PCa in codominant [odds ratio $(\mathrm{OR})=2.23,95 \%$ confidence interval $(\mathrm{CI})=1.13-4.37$; $\mathrm{P}=0.021$, insertion (ins)/ins vs. deletion (del)/del] and recessive $(\mathrm{OR}=2.33,95 \% \mathrm{CI}=1.25-4.36 ; \mathrm{P}=0.009$, ins/ins vs. $\mathrm{del} / \mathrm{del}+$ $\mathrm{del} / \mathrm{ins})$. In conclusion, to the best of our knowledge, the present findings for the first time proposed that a 3-bp indel variant of miR-3131 may be a risk factor for susceptibility to $\mathrm{PCa}$ in a sample of an Iranian population. Further studies with different ethnicities and larger sample sizes are required to validate the present findings.
\end{abstract}

\section{Introduction}

Prostate cancer ( $\mathrm{PCa}$ ), the second most common malignancy in men, is the fifth leading cause of cancer-related mortality among men globally (1). The incidence rate of PCa in Iran

Correspondence to: Professor Mohammad Hashemi, Department of Clinical Biochemistry, School of Medicine, Zahedan University of Medical Sciences, Khalij Fars Boulevard, Zahedan 98167-43181, Iran

E-mail: mhd.hashemi@gmail.com

Key words: pre-microRNA-3131, indel, polymorphism, prostate cancer is lower than that in the rest of the world (2-4). Despite the high prevalence of $\mathrm{PCa}$, little is known about the mechanisms underlying the development and progression of $\mathrm{PCa}$. It has been proposed that genomic and environmental factors contribute to the development and progression of PCa (5-8). Twin studies have indicated that $42 \%$ of the variation in PCa risk may be attributed to genetics (9). Single nucleotide polymorphisms (SNPs), the most common type of genetic variation in the human genome, have been demonstrated to be associated with the risk of developing $\mathrm{PCa}(10-12)$.

MicroRNA (miR) are small, non-coding, endogenous, single-stranded RNA molecules that are 22 nucleotides in length $(13,14)$. They regulate gene expression by directing sequence-specific degradation or inhibiting translation of target mRNA $(13,14)$. Mounting evidence has suggested that mutation or SNPs in miR genes may affect target-binding activity, expression, or processes of mature miR, thus affecting the expression of their target genes $(15,16)$. Polymorphisms in mature and/or pre-miR sequences may affect miR biogenesis and be associated with the development of various types of cancer (17-21). Small insertions and deletion (indels) polymorphisms are one of the most common genetic alterations in the human genome that influence human traits and diseases $(22,23)$. There is limited information regarding the association between pre-miR-3131 polymorphisms and cancer risk. Recently, Wang et al (20) investigated the impact of a 3-bp indel polymorphism (rs57408770) in pre-miR-3131 on hepatocellular carcinoma (HCC) and observed that the insertion (ins) allele significantly increased the risk of HCC in a Chinese population. To the best of our knowledge, for the first time, the present study aimed to determine the impact of a 3-bp indel polymorphism (rs57408770) within pre-miR-3131 on PCa susceptibility in a sample of an Iranian population.

\section{Patients and methods}

Patients. The present case-control study involved 177 patients with PCa (mean age, 61.45 \pm 6.78 years) and 177 individuals with benign prostatic hyperplasia (BPH) as controls (mean age, 
$62.43 \pm 7.68$ years) admitted to hospital between February 2014 and March 2015. All cases and controls were elected from the Department of Urology, Shahid Labbafinejad Medical Center, Shahid Beheshti University of Medical Sciences (Tehran, Iran). The study design and enrolment procedure were described previously $(17,18,24)$. The project was approved by the local Ethics Committee of Zahedan University of Medical Sciences (Zahedan, Iran) and written informed consent was taken from all participants. Peripheral blood samples were collected in tubes containing EDTA and genomic DNA was extracted using the salting out method, as described previously (25).

Genotyping. Mismatch polymerase chain reaction-restriction fragment length polymorphism (PCR-RFLP) methods for genotyping were designed. Mismatched $\mathrm{C}$ was introduced into the forward primers of rs57408770 at -2 bp from the polymorphic site to create an AluI (New England BioLabs, Inc., Ipswich, MA, USA) restriction site. The forward and reverse primers were 5'-CTGTGCAGCTGACTCTGAGAA GACG-3' and 5'-TATTGGCTCCTAGGAAGGCTGAGT-3', respectively.

PCR was performed using commercially available prime Taq Premix (GeNet Bio, Nonsan, Korea), according to the manufacturer's instructions. Each $0.20 \mathrm{ml}$ PCR reaction tube contained $1 \mu \mathrm{l}$ genomic DNA (100 ng/ml), $1 \mu \mathrm{l}$ each primer $(10 \mu \mathrm{M}), 7 \mu \mathrm{l} 2 \mathrm{X}$ master mix and the appropriate amount of double-distilled $\mathrm{H}_{2} \mathrm{O}$. Amplification was performed with an initial denaturation at $95^{\circ} \mathrm{C}$ for $6 \mathrm{~min}$, followed by 30 cycles of $30 \mathrm{sec}$ at $95^{\circ} \mathrm{C}, 30 \mathrm{sec}$ at $65^{\circ} \mathrm{C}$ and $72^{\circ} \mathrm{C}$ for $30 \mathrm{sec}$, with a final extension step of $72^{\circ} \mathrm{C}$ for $5 \mathrm{~min}$. For genotyping, $10 \mu \mathrm{l} \mathrm{PCR}$ product was digested by $A l u \mathrm{I}$ and the digested products were separated by $2.5 \%$ agarose gel electrophoresis. The deletion (del) allele produced a 188-bp fragment, while the ins allele produced 171- and 20-bp fragments (Fig. 1).

Statistical analysis. Statistical analysis was conducted using SPSS v. 22 software (IBM Corp., Armonk, NY, USA). Data were analyzed by independent samples t-tests and $\chi^{2}$ tests. Unconditional logistic regression analysis was used to examine the association between the rs 57408770 variant and PCa risk. $\mathrm{P}<0.05$ was considered to indicate a statistically significant difference.

\section{Results}

Patient characteristics. The present study consisted of 177 patients with $\mathrm{PCa}$ (mean age, 61.45 \pm 6.78 years) and 177 individuals with BPH (mean age, 62.43 \pm 7.68 years). No significant difference was observed between the age of the two groups $(\mathrm{P}=0.212$; data not shown).

3-bp indel (rs57408770) polymorphism and risk of PCa. The genotypes and allele frequencies of the 3-bp indel (rs57408770) polymorphism within pre-miR-3131 in patients with PCa and control subjects are demonstrated in Table I. The findings revealed that the indel variant was significantly associated with increased risk of $\mathrm{PCa}$ in codominant [odds ratio $(\mathrm{OR})=2.23$, $95 \%$ confidence interval $(\mathrm{CI})=1.13-4.37 ; \mathrm{P}=0.021$, ins/ins vs reference del $/ \mathrm{del})$ and recessive $(\mathrm{OR}=2.33,95 \% \mathrm{CI}=1.25-4.36$; $\mathrm{P}=0.009$, ins/ins vs. reference $\mathrm{del} / \mathrm{del}+\mathrm{del} / \mathrm{ins})$. The ins allele

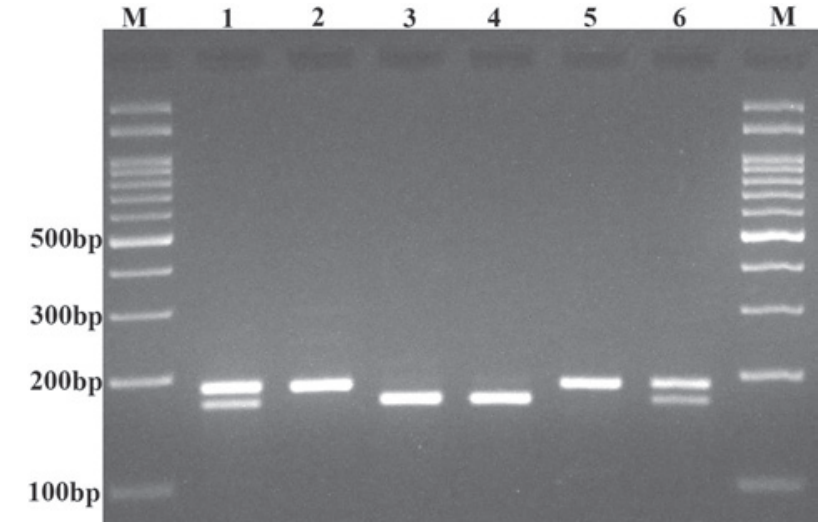

Figure 1. Electrophoresis pattern of the mismatch polymerase chain reaction-restriction fragment length polymorphism method for detection of a 3-bp indel polymorphism within pre-microRNA-3131. M, DNA marker; lanes 1 and 6, insertion/deletion; lanes 2 and 5, deletion/deletion; lanes 3 and 4, insertion/insertion.

was not significantly associated with the risk of $\mathrm{PCa}(\mathrm{OR}=1.33$, 95\% CI=0.98-1.81; $\mathrm{P}=0.083)$.

Association between 3-bp indel polymorphism of pre-miR-3131 and clinicopathological characteristics. The association between the 3-bp indel polymorphism of pre-miR-3131 and clinicopathological characteristics, including age, stage, prostate specific antigen levels, Gleason score (18), perineural invasion and surgical margin, are demonstrated in Table II. The findings revealed that the 3-bp indel polymorphism of pre-miR-3131 was only significantly associated with perineural invasion $(\mathrm{P}=0.015)$. No significant association was observed between the variant and other clinicopathological characteristics in patients with PCa. The Hardy-Weinberg equilibrium (HWE) was calculated and the results indicated that the genotype distribution in cases and controls was consistent with $\operatorname{HWE}\left(\chi^{2}=2.41, \mathrm{P}=0.121\right.$ and $\chi^{2}=1.97, \mathrm{P}=0.161$, respectively; data not shown).

\section{Discussion}

Recent expression profiling studies in $\mathrm{PCa}$ suggest that miR may serve as potential biomarkers for PCa risk and disease progression (26-30). Growing evidence has indicated that mutation or polymorphisms in miR genes could affect target-binding activity, expression or processes of mature miR, consequently affecting the expression of their target genes $(15,16)$. Polymorphisms in miR have been demonstrated to be associated with the development of PCa $(17,18,31,32)$. In present study, it was hypothesized that the 3-bp indel polymorphism of pre-miR-3131 may be associated with the development of PCa. The present results indicated that the ins/ins genotype of the pre-miR-313 variant significantly increased the risk of PCa. To the best of our knowledge, there has only been one report regarding the impact of a 3-bp indel polymorphism of pre-miR-3131 on cancer risk (20). Wang et al (20) demonstrated that the insertion allele of a 3-bp indel polymorphism of pre-miR-3131 was significantly associated with an increased risk for HCC. Furthermore, their findings revealed that the 3-bp indel polymorphism could affect the expression level of miR-3131 by influencing the binding of 
Table I. Genotype and allele frequencies of a 3-bp indel (rs57408770) polymorphism of pre-microRNA-3131 in patients with $\mathrm{PCa}$ and controls.

\begin{tabular}{|c|c|c|c|c|}
\hline \multirow[b]{2}{*}{ Polymorphism } & \multicolumn{2}{|c|}{ Group } & \multirow[b]{2}{*}{ Odds ratio ( $95 \%$ confidence interval) } & \multirow[b]{2}{*}{$\mathrm{P}$-value } \\
\hline & PCa, n (\%) & Controls, n (\%) & & \\
\hline \multicolumn{5}{|l|}{ Codominant } \\
\hline $\mathrm{del} / \mathrm{del}^{\mathrm{a}}$ & $62(36.5)$ & $67(39.4)$ & 1.00 & - \\
\hline $\mathrm{del} /$ ins & $73(42.9)$ & $86(50.6)$ & $0.92(0.58-1.46)$ & 0.723 \\
\hline ins/ins & $35(20.6)$ & $17(10.0)$ & $2.23(1.13-4.37)$ & 0.021 \\
\hline \multicolumn{5}{|l|}{ Dominant } \\
\hline $\mathrm{del} / \mathrm{del}^{\mathrm{a}}$ & $62(36.5)$ & $67(39.4)$ & 1.00 & - \\
\hline $\mathrm{del} / \mathrm{ins}+\mathrm{ins} / \mathrm{ins}$ & $108(63.5)$ & $103(60.6)$ & $1.3(0.73-1.76)$ & 0.654 \\
\hline \multicolumn{5}{|l|}{ Recessive } \\
\hline $\mathrm{del} / \mathrm{del}+\mathrm{del} / \mathrm{ins}^{\mathrm{a}}$ & $135(79.4)$ & $153(90.0)$ & 1.00 & - \\
\hline ins/ins & $35(20.6)$ & $17(10.0)$ & $2.33(1.25-4.36)$ & 0.009 \\
\hline \multicolumn{5}{|l|}{ Allele } \\
\hline $\operatorname{del}^{\mathrm{a}}$ & $197(58.0)$ & $220(64.7)$ & 1.00 & - \\
\hline ins & $143(42.0)$ & $120(35.3)$ & $1.33(0.98-1.81)$ & 0.083 \\
\hline
\end{tabular}

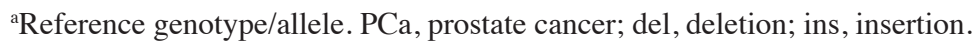

Table II. Association of 3-bp indel (rs57408770) polymorphism of pre-microRNA-3131 with clinicopathological characteristics of patients with prostate cancer.

\begin{tabular}{|c|c|c|c|c|}
\hline \multirow[b]{2}{*}{ Factors } & \multicolumn{3}{|c|}{ rs3787016 C>T } & \multirow[b]{2}{*}{ P-value } \\
\hline & $\mathrm{del} / \mathrm{del}, \mathrm{n}$ & del/ins, n & ins/ins, $\mathrm{n}$ & \\
\hline Age at diagnosis, years & & & & 0.876 \\
\hline$\leq 65$ & 43 & 52 & 26 & \\
\hline$>65$ & 19 & 21 & 9 & \\
\hline Stage & & & & 0.578 \\
\hline pT1 & 2 & 3 & 3 & \\
\hline pT2a & 9 & 9 & 9 & \\
\hline pT2b & 6 & 3 & 2 & \\
\hline pT2c & 26 & 37 & 14 & \\
\hline pT3a & 5 & 7 & 1 & \\
\hline pT3b & 14 & 14 & 6 & \\
\hline Prostate specific antigen level at diagnosis, $\mathrm{ng} / \mathrm{ml}$ & & & & 0.458 \\
\hline$\leq 4$ & 0 & 1 & 0 & \\
\hline $4-10$ & 31 & 32 & 21 & \\
\hline$>10$ & 30 & 40 & 14 & \\
\hline Gleason score & & & & 0.538 \\
\hline$\leq 7$ & 44 & 58 & 28 & \\
\hline$>7$ & 17 & 15 & 7 & \\
\hline Perineural invasion & & & & 0.015 \\
\hline Positive & 47 & 40 & 19 & \\
\hline Negative & 14 & 33 & 16 & \\
\hline Surgical margin & & & & 0.180 \\
\hline Positive & 29 & 28 & 10 & \\
\hline Negative & 32 & 45 & 25 & \\
\hline
\end{tabular}

del, deletion; ins, insertion. 
splicing factor SRp20 with pre-miR-3131 (20). Hsa-miR-3131 is located on chromosome 2 in intron 2 of the Indian hedgehog gene and the 3-bp indel variant (rs57408770) is located in the 3' end of miR-3131 (20). A study by Shen et al (33) demonstrated that the miR-3131 expression level was upregulated by 92 -fold in HepG2 cells treated with Ganoderma lucidum polysaccharide, proposing that miR-3131 may be involved in the proliferation and differentiation of HCC cells.

Polymorphisms in miR genes, including pri-miR (17,34,35), pre-miR (36) and mature miR, may affect the processing of $\mathrm{miR}$ as well as the regulatory function on their target genes, and consequently may be implicated in the development and prognosis of various types of cancer (37-39). In conclusion, to the best of our knowledge, the present study provided evidence for the first time that the 3-bp indel polymorphism of pre-miR-3131 significantly increased the risk of developing $\mathrm{PCa}$ in a sample of an Iranian population. Therefore, the pre-miR-3131 3-bp indel variant may be a potential biomarker for prostate cancer. Further studies with different ethnicities and larger sample sizes are required to certify the present findings.

\section{Acknowledgements}

The present study was supported by a grant from Zahedan University of Medical Sciences (Zahedan, Iran; grant no. 7832).

\section{References}

1. Siegel RL, Miller KD and Jemal A: Cancer statistics, 2015. CA Cancer J Clin 65: 5-29, 2015

2. Farahmand M, Khademolhosseini F and Mehrabani D: Trend of prostate cancer in Fars Province, Southern Iran, 2001-2007. J Res Med Sci 15: 295-297, 2010.

3. Talaiezadeh A, Tabesh H, Sattari A and Ebrahimi S: Cancer incidence in southwest of iran: First report from khuzestan population-based cancer registry, 2002-2009. Asian Pac J Cancer Prev 14: 7517-7522, 2013.

4. Baade PD, Youlden DR, Cramb SM, Dunn J and Gardiner RA: Epidemiology of prostate cancer in the Asia-Pacific region. Prostate Int 1: 47-58, 2013.

5. Ntais C, Polycarpou A and Tsatsoulis A: Molecular epidemiology of prostate cancer: Androgens and polymorphisms in androgen-related genes. Eur J Endocrinol 149: 469-477, 2003.

6. Chokkalingam AP, Stanczyk FZ, Reichardt JK and Hsing AW: Molecular epidemiology of prostate cancer: Hormone-related genetic loci. Front Biosci 12: 3436-3460, 2007.

7. Zhou X, Wei L, Jiao G, Gao W, Ying M, Wang N, Wang Y and Liu C: The association between the APE1 Asp148Glu polymorphism and prostate cancer susceptibility: A meta-analysis based on case-control studies. Mol Genet Genomics 290: 281-288, 2015.

8. Bratt O: Hereditary prostate cancer: Clinical aspects. J Urol 168: 906-913, 2002

9. Lichtenstein P, Holm NV, Verkasalo PK, Iliadou A, Kaprio J, Koskenvuo M, Pukkala E, Skytthe A and Hemminki K: Environmental and heritable factors in the causation of cancer-analyses of cohorts of twins from Sweden, Denmark, and Finland. N Engl J Med 343: 78-85, 2000.

10. Huang Q, Whitington T, Gao P, Lindberg JF, Yang Y, Sun J, Väisänen MR, Szulkin R, Annala M, Yan J, et al: A prostate cancer susceptibility allele at 6q22 increases RFX6 expression by modulating HOXB13 chromatin binding. Nat Genet 46: $126-135,2014$

11. Hazelett DJ, Rhie SK, Gaddis M, Yan C, Lakeland DL, Coetzee SG; Ellipse/GAME-ON consortium; Practical consortium; Henderson BE, Noushmehr H, et al: Comprehensive functional annotation of 77 prostate cancer risk loci. PLoS Genet 10: e1004102, 2014.
12. Eeles RA, Olama AA, Benlloch S, Saunders EJ, Leongamornlert DA, Tymrakiewicz M, Ghoussaini M, Luccarini C, Dennis J, Jugurnauth-Little S, et al: Identification of 23 new prostate cancer susceptibility loci using the iCOGS custom genotyping array. Nat Genet 45: 385-91, 391e1-2, 2013.

13. Bartel DP: MicroRNAs: Genomics, biogenesis, mechanism, and function. Cell 116: 281-297, 2004.

14. Lim LP, Lau NC, Garrett-Engele P, Grimson A, Schelter JM, Castle J, Bartel DP, Linsley PS and Johnson JM: Microarray analysis shows that some microRNAs downregulate large numbers of target mRNAs. Nature 433: 769-773, 2005.

15. Hu Z, Chen J, Tian T, Zhou X, Gu H, Xu L, Zeng Y, Miao R, Jin G, Ma H, et al: Genetic variants of miRNA sequences and non-small cell lung cancer survival. J Clin Invest 118: 2600-2608, 2008.

16. Sibin MK, Harshitha SM, Narasingarao KV, Dhananjaya IB, Dhaval PS and Chetan GK: Effect of rs11614913 polymorphism on mature miR196a2 Expression and its target gene HOXC8 expression in human glioma. J Mol Neurosci 61: 144-151, 2017.

17. Hashemi M, Danesh H, Bizhani F, Narouie B, Sotoudeh M, Nouralizadeh A, Sharifiaghdas F, Bahari G and Taheri M: Pri-miR-34b/c rs4938723 polymorphism increased the risk of prostate cancer. Cancer Biomark 18: 155-159, 2017.

18. Hashemi M, Moradi N, Ziaee SA, Narouie B, Soltani MH, Rezaei M, Shahkar G and Taheri M: Association between single nucleotide polymorphism in miR-499, miR-196a2, miR-146a and miR-149 and prostate cancer risk in a sample of Iranian population. J Adv Res 7: 491-498, 2016

19. Liu F, Dear K, Huang L, Liu L, Shi Y, Nie S, Liu Y, Lu Y and Xiang H: Association between microRNA-27a rs895819 polymorphism and risk of colorectal cancer: A meta-analysis. Cancer Genet 209: 388-394, 2016.

20. Wang C, Li L, Yin Z, Zhang Q, Zhao H, Tao R, Wang S, Hu S, He Y, Wang D, et al: An Indel Polymorphism within pre-miR3131 confers risk for hepatocellular carcinoma. Carcinogenesis 38: 168-176, 2017.

21. Omrani M, Hashemi M, Eskandari-Nasab E, Hasani SS, Mashhadi MA, Arbabi F and Taheri M: hsa-mir-499 rs3746444 gene polymorphism is associated with susceptibility to breast cancer in an Iranian population. Biomark Med 8: 259-267, 2014.

22. Mullaney JM, Mills RE, Pittard WS and Devine SE: Small insertions and deletions (INDELs) in human genomes. Hum Mol Genet 19: R131-R136, 2010.

23. Eskandari-Nasab E, Hashemi M, Ebrahimi M and Amininia S: The functional 4-bp insertion/deletion ATTG polymorphism in the promoter region of NF-KB1 reduces the risk of BC. Cancer Biomark 16: 109-115, 2016.

24. Hashemi M, Shahkar G, Simforoosh N, Basiri A, Ziaee SA, Narouie B and Taheri M: Association of polymorphisms in PRKCI gene and risk of prostate cancer in a sample of Iranian Population. Cell Mol Biol (Noisy-le-grand) 61: 16-21, 2015.

25. Hashemi M, Hanafi Bojd H, Eskandari Nasab E, Bahari A, Hashemzehi NA, Shafieipour S, Narouie B, Taheri M and Ghavami S: Association of Adiponectin rs1501299 and rs266729 gene polymorphisms with nonalcoholic fatty liver disease. Hepat Mon 13: e9527, 2013.

26. Luu HN, Lin HY, Sørensen KD, Ogunwobi OO, Kumar N, Chornokur G, Phelan C, Jones D, Kidd L, Batra J, et al: miRNAs associated with prostate cancer risk and progression. BMC Urol 17: 18, 2017.

27. Wei W, Leng J, Shao H and Wang W: MiR-1, a potential predictive biomarker for recurrence in prostate cancer after radical prostatectomy. Am J Med Sci 353: 315-319, 2017.

28. Valentino A, Reclusa P, Sirera R, Giallombardo M, Camps C Pauwels P, Crispi S and Rolfo C: Exosomal microRNAs in liquid biopsies: Future biomarkers for prostate cancer. Clin Transl Oncol 19: 651-657, 2017.

29. Shukla KK, Misra S, Pareek P, Mishra V, Singhal B and Sharma P: Recent scenario of microRNA as diagnostic and prognostic biomarkers of prostate cancer. Urol Oncol 35: 92-101, 2017.

30. Qiu X and Dou Y: miR-1307 promotes the proliferation of prostate cancer by targeting FOXO3A. Biomed Pharmacother 88: 430-435, 2017.

31. Chu H, Zhong D, Tang J, Li J, Xue Y, Tong N, Qin C, Yin C, Zhang $\mathrm{Z}$ and Wang M: A functional variant in miR-143 promoter contributes to prostate cancer risk. Arch Toxicol 90: 403-414, 2016. 
32. Porkka KP, Ogg EL, Saramaki OR, Saramäki OR, Vessella RL, Pukkila $H$, Lähdesmäki $H$, van Weerden WM, Wolf $M$, Kallioniemi OP, et al: The miR-15a-miR-16-1 locus is homozygously deleted in a subset of prostate cancers. Genes Chromosomes Cancer 50: 499-509, 2011.

33. Shen J, Park HS, Xia YM, Kim GS and Cui SW: The polysaccharides from fermented Ganoderma lucidum mycelia induced miRNAs regulation in suppressed HepG2 cells. Carbohydr Polym 103: 319-324, 2014.

34. Lee Y, Kim M, Han J, Yeom KH, Lee S, Baek SH and Kim VN: MicroRNA genes are transcribed by RNA polymerase II. EMBO J 23: 4051-4060, 2004.

35. Hashemi M, Bahari G, Naderi M, Sadeghi-Bojd S and Taheri M: Pri-miR-34b/c rs4938723 polymorphism is associated with the risk of childhood acute lymphoblastic leukemia. Cancer Genet 209: 493-496, 2016.

36. Ryan BM, Robles AI and Harris CC: Genetic variation in microRNA networks: The implications for cancer research. Nat Rev Cancer 10: 389-402, 2010.
37. Okubo M, Tahara T, Shibata T, Yamashita H, Nakamura M, Yoshioka D, Yonemura J, Ishizuka T, Arisawa T and Hirata I: Association between common genetic variants in pre-microRNAs and gastric cancer risk in Japanese population. Helicobacter 15: 524-531, 2010.

38. Qiu F, Yang L, Zhang L, Yang X, Yang R, Fang W, Wu D, Chen J, Xie C, Huang D, et al: Polymorphism in mature microRNA-608 sequence is associated with an increased risk of nasopharyngeal carcinoma. Gene 565: 180-186, 2015.

39. Hashemi M, Sanaei S, Rezaei M, Bahari G, Hashemi SM, Mashhadi MA, Taheri M and Ghavami S: miR-608 rs4919510 $\mathrm{C}>\mathrm{G}$ polymorphism decreased the risk of breast cancer in an Iranian subpopulation. Exp Oncol 38: 57-59, 2016. 